\title{
Study of radon exhalation from soil to ascertain the elevated levels of background radiation of Bangladesh
}

\author{
M.I. Chowdhury, M.R. Chowdhury and M.N. Alam \\ Radioactivity Testing and Monitoring Laboratory, Bangladesh Atomic Energy Commission, \\ P.O. Box 1352, Chittagong. Bangladesh \\ ${ }^{1}$ Department of Physics, University of Chittagong, Chittagtong, Bangladesh
}

\begin{abstract}
Abatract. The outdoor environmental background radiation level in nomal area of Bangladesh ranged between 110 and $445 \mathrm{nGy} \mathrm{h}^{-1}$ was observed in a countrywide background radiation survey using $\beta-\gamma$ radiation survey meter. The United Nation Scientific Committee on the Effects of Alomic Radiation (UNSCEAR) reported to the united Nations General Assembly in its 1988 report that the outdoor country averaged environmental background radiation level in air in 23 countries representing about one half of the world population were found to range between 24 and 85 $\mathrm{nGy} \cdot \mathrm{h}^{-1}$, with a mean value of $55 \mathrm{nGy} \cdot \mathrm{h}^{-1}$, which is one fourth of the radiation dose level of Bangladesh. In the present study, activity concentration of radium and radon radionuclides was measured in the soil samples of the country and measured their radon emanation coefficient, and radon mass exhalation and radon area exhalation rates with an aim to evaluate the cause of high background radiation level in Bangladesh. The result shows that the concentration of ${ }^{226} \mathrm{Ra}$ in most of the soil samples was higher than that of world average value, and the concentration of ${ }^{24} \mathrm{Ra}$, a daughter of ${ }^{232} \mathrm{Th}$-series, is more than two times higher than the world average value. The activity of ${ }^{40} \mathrm{~K}$ was found higher than both the range and average world value in most of the samples. The results of ${ }^{222} \mathrm{Rn}$ emanation coefficients, ${ }^{222} \mathrm{Rn}$ mass and area exhalation rates are very significant. Values of radon emanation coefficients for the soil samples in a number of locations were found in excess of world average value. The ${ }^{222} \mathrm{Rn}$ emanation coefficients was found in the range $3.10-44.68 \%$, the mass exhalation rates was found in the range 2.50 $-27.84 \mu \mathrm{Bq} \cdot \mathrm{kg}^{-1} \cdot \mathrm{sec}^{-1}$, and the area exhalation rates was found in the range $3.15-38.15 \mathrm{mBq} \cdot \mathrm{m}^{-2} \cdot \mathrm{sec}^{-1}$. Due to high concentrations of radium and potassium in soil and the high radon exhalation rate the external and internal doses are also higher. The total extemal dose from soil was found higher than the reported results of most of the countries of the World. This result would be helpful to assess the radiation exposure to human, animal and plants, and radiation related cancer risk.
\end{abstract}

\section{INTRODUCTION}

The assessment of the radiation doses in human from environmental radiation is of special importance because radiation is harmful to man and environment. The major contribution to the various radiation exposures received by mankind comes from natural sources. Natural irradiation has been exposing the whole population of the world at a relatively constant rate over a long period of time. Large-scale surveys have been carried out in 23 countries in order to estimate average nation-wide exposures to outdoor external gamma-radiation, representing about one half of the world population, showed that countryaveraged outdoor-absorbed dose rates in air were found to range between 24 and $85 \mathrm{nGyb}^{-1}$, with an arithmetic mean of $55 \mathrm{nGyh}^{-1}$ [1]. Inhalation of short-lived decay products of radon $\left({ }^{222} \mathrm{Rn}\right)$ accounts on average for one half of the effective dose equivalent from all natural sources of radiation and may sometimes lead to doses high enough to cause concern for human health [2]. The sources of natural radiations are the members of three well-known natural radioactive series namely thorium, uranium and actinium series associated with their progeny [1]. Radon isotopes are the members of the natural radioactive series. Radon isotopes diffuse from the earth into the atmosphere producing a number of short-lived decay products. The concentration of the two radon isotopes in air is highly variable, and determined largely by the concentration of their precursors ${ }^{226} \mathrm{Ra}$ and ${ }^{232} \mathrm{Th}$ in the soil. Atmospheric concentrations are expectedly greatest over areas in which the soil is rich in radium and thorium. Diffusive ${ }^{222} \mathrm{Rn}$ migration in porous media normally does not exceed several meters, while ${ }^{220} \mathrm{R}$ only reaches some centimeters. The diffusive ${ }^{222} \mathrm{Rn}$ component in soil gas can be calculated from the specific ${ }^{226} \mathrm{Ra}$ activity, specific density, effective porosity and radon escape/production ratio of soils and rocks [3]. In Bangladesh the external background radiation levels lie between 1.0 and $3.9 \mathrm{mSv} . \mathrm{y}^{-1}$ with an average value of $2 \mathrm{mSv}^{-\mathrm{y}^{-1}}$ excluding Cox's Bazar beach sand areas where an average value of $13 \mathrm{mSv} . \mathrm{y}^{-1}$ with a range of $2.6-44.0$ $\mathrm{mSv} . \mathrm{y}^{-1}$ was observed $[4,5]$. In the present study, activity concentration of radium and radon radionuclides was measured in the soil samples of the country and measured their radon emanation coefficient, and 
radon mass exhalation and radon area exhalation rates with an aim to evaluate the cause of high background radiation level in Bangladesh.

\section{METHODS AND MATERIALS}

In the present study, 150 samples of soil were collected from upper layer of soil up to $15 \mathrm{~cm}$ depth by using soil corer from the several districts of Bangladesh. The samples were cleaned, dried in air and crushed to fine powder. The powdered soils were filled into cylindrical plastic containers (dia. $6.5 \mathrm{~cm}$, ht. $7.5 \mathrm{~cm}$ ) of active volume $150 \mathrm{ml}$. To determine the fraction of ${ }^{222} \mathrm{Rn}$ could escape from the material, activity measurements were made on ventilated samples before they were baked and before the cans were sealed. After the measurements, the samples were then baked and sealed for determination of radionuclide contents. The difference between the total amount of ${ }^{222} \mathrm{Rn}$ generated by the material $\left({ }^{226} \mathrm{Ra}\right.$ activity of the 4-week sealed samples) and the ${ }^{222} \mathrm{Rn}$ trapped in the material $\left({ }^{214} \mathrm{~Pb}\right.$ and ${ }^{214} \mathrm{Bi}$ activity of the ventilated samples) yielded the amount of ${ }^{222} \mathrm{Rn}$ that has escaped [6]. The fraction of radon produced, which can escape from the solid matrix of soil, is the emanation coefficient of soil [1]. Only this fraction of ${ }^{222} \mathrm{Rn}$ can diffuse through the soil and escape to the open air. The emanation rate is the product of the emanation coefficient and ${ }^{222} \mathrm{Rn}$-production rate. The containers were sealed tightly and wrapped with thick vinyl tapes around their screw necks. The samples were stored for four weeks to allow ${ }^{226} \mathrm{Ra}$ and ${ }^{232} \mathrm{Th}$ to reach in secular equilibrium with their respective daughters [7], then the samples were counted using a ptype coaxial high purity germanium (HPGe) detector of active volume $132 \mathrm{cc}$, relative efficiency $35 \%$ and resolution $1.8 \mathrm{keV}$ (FWHM) at $1.33 \mathrm{MeV} \gamma$-energy of ${ }^{60} \mathrm{Co}$ coupled with $\mathrm{PC}$ based multichannel analyser (PCMCA). The $\gamma$-ray energy regions selected for the corresponding radionuclides were 583 and $2614 \mathrm{keV}$ of ${ }^{208} \mathrm{Tl}$, and 911 and $969 \mathrm{keV}$ of ${ }^{228} \mathrm{Ac}$ for the determination of ${ }^{224} \mathrm{Ra} ; 295$ and $352 \mathrm{keV}$ of ${ }^{214} \mathrm{~Pb}$ and 609.3 , 1120 and $1764.5 \mathrm{keV}$ of ${ }^{214} \mathrm{Bi}$ for the determination of ${ }^{226} \mathrm{Ra}$, and $1460 \mathrm{keV}$ for ${ }^{40} \mathrm{~K}[7,8]$. Measurements were carried out in a low background lead shielding arrangement. The efficiencies of the detector for the corresponding gamma energies were measured using IAEA reference samples RGU-1, RGTh-1 and RGK-1 of uranium ore, thorium ore mixed in silica matrix and potassium sulfate respectively, at identical sample counting geometry [9]. The concentrations of corresponding radionuclides were calculated from the net peak area.

\section{RESULTS AND DISCUSSION}

The mean results of activity concentrations of ${ }^{226} \mathrm{Ra},{ }^{224} \mathrm{Ra}$ and ${ }^{40} \mathrm{~K}$ radionuclides in soil and derived radiation hazard parameters, the radon emanation coefficients and radon mass and area exhalation rates of soils are shown in Table 1 . In the soil, the activity of ${ }^{226} \mathrm{Ra}$ ranged from $7.80-66.52 \mathrm{~Bq} \cdot \mathrm{kg}^{-1}$, ${ }^{224} \mathrm{Ra}$ ranged from $27.0-98.95 \mathrm{~Bq} \cdot \mathrm{kg}^{-1}$ and the ${ }^{40} \mathrm{~K}$ ranged from $218-1453 \mathrm{~Bq} \cdot \mathrm{kg}^{-1}$. In most of the samples values of ${ }^{226} \mathrm{Ra}$ found are higher than the world average value of $25 \mathrm{~Bq} \cdot \mathrm{kg}^{-1}$ [1], and the values of ${ }^{224} \mathrm{Ra}$, a daughter product of ${ }^{232} \mathrm{Th}$-series, is more than two times higher than the world average value. The ${ }^{40} \mathrm{~K}$, a significant dose contributor to the environment and an naturally abundant primordial radionuclide, was found in high contents than the range and mean of world value in most of the locations. The world range and average ${ }^{222} \mathrm{Rn}$ emanation coefficients are $2-80 \%$ and $20 \%$ respectively [ 1 ]. In the present work, ${ }^{222} \mathrm{Rn}$ emanating coefficient value in a number location was found in excess of world average value. The ${ }^{222} \mathrm{Rn}$ emanation coefficient ranged from $3.10-44.68 \%$ and ${ }^{220} \mathrm{Rn}$ emanation coefficient ranged from $0.13-$ $18.48 \%$. The mass activity emanation rate, expressed in $\mathrm{Bq} \mathrm{kg}^{-1} \mathrm{~s}^{-1}$ and defined as [1]

$$
\mathbf{R}_{\mathbf{m}}=\lambda_{\mathrm{Rn}} \mathbf{C}_{\text {:oili, }} \mathbf{R}_{\mathbf{r}} \mathbf{F}_{\mathbf{r}}
$$

where $R_{m}$ is the mass exhalation rate in $B q \cdot \mathrm{kg}^{-1} \cdot \mathrm{sec}^{-1}, \lambda_{R_{n}}$ is the decay constant of radon, $\mathrm{C}_{\mathrm{R}_{n}}$ is the concentration of $\mathrm{Ra}$ in soil and $F_{r}$ is the emanation coefficient. The ${ }^{222} \mathrm{Rn}$ mass exhalation rate is ranged from $2.50-27.84 \mu \mathrm{Bq} \cdot \mathrm{kg}^{-1} \cdot \mathrm{sec}^{-1}$ and the ${ }^{220} \mathrm{Rn}$ mass exhalation rate is ranged from $1.02-17.17 \mathrm{mBq} \cdot \mathrm{kg}^{-}$ $1 \sec ^{-1}$ 
The area exhalation rate, defined as the activity transfer rate per unit area at the soil-air interface, is expressed as [1]:

$$
R=\lambda_{R \mathbf{R}} F_{r} C_{\text {soll, Rs }} \rho_{\text {soil }} L_{R n}
$$

where $R$ is the area exhalation rate in $B q ~ ~^{-2} \mathrm{~s}^{-1} ; \lambda_{\mathrm{Rn}}$ is the decay constant of ${ }^{222} \mathrm{Rn}\left(2.1 \times 10^{-6} \mathrm{~s}^{-1}\right) ; \mathrm{F}_{\mathrm{r}}$ is the emanating power; $\mathrm{C}_{\text {soil, } \mathrm{Ra}}$ is the activity mass concentration of ${ }^{226} \mathrm{Rn}$ in soil $\left(\mathrm{Bq} \mathrm{kg}^{-1}\right)$; $\rho_{\text {soil }}$ is the soil density $\left(\mathrm{kg} \mathrm{m}^{-3}\right)$; and $\mathrm{L}_{\mathrm{Rn}}$ is the diffusion length of radon in soil $(\mathrm{m})$. The ${ }^{222} \mathrm{Rn}$ area exhalation rate is ranged from $3.15-38.15 \mathrm{mBq} \cdot \mathrm{m}^{-2} \cdot \mathrm{s}^{-1}$ and ${ }^{220} \mathrm{Rn}$ area exhalation rate is ranged from $0.30-11.71 \mathrm{mBq} \cdot \mathrm{m}^{-}$ ${ }^{2} . \mathrm{s}^{-1}$. The world average value of ${ }^{222} \mathrm{Rn}$ area exhalation rate is $16 \mathrm{mBq} \cdot \mathrm{m}^{-2} \cdot \mathrm{sec}^{-1}$. Area exhalation rate in a number of soil samples were found higher than that of world average value.

The external dose rate at $1 \mathrm{~m}$ above the ground surface due to the natural radionuclides in soil is ranged from $46-137 \mathrm{nGy} \cdot \mathrm{h}^{-1}$ with an average dose of $82 \mathrm{nGy} \cdot \mathrm{h}^{-1}$ were observed. The total external dose from soil was found higher than the reported results of most of the countries of the World. In India, the absorbed dose rate in air from all the natural sources is $20-1100 \mathrm{nGy} \cdot \mathrm{h}^{-1}$ and its average is $55 \mathrm{nGy} \cdot \mathrm{h}^{.1}$. In China, the concentration of ${ }^{226} \mathrm{Ra}$ was reported by Ziqianj et al is $18.2-135 \mathrm{~Bq} \cdot \mathrm{kg}^{-1}$ and the dose rate in air $6.07-15.1$ nGy. $y^{-1}$. The reported highest absorbed dose rate area of the World are Norway and Sweden, there ranges are $20-1200$ and $18-4000 \mathrm{nGy} \cdot \mathrm{y}^{-1}$. The range of absorbed doses of Austria is $20-$ 150, France is $10-250$, Germany $4-350$, Italy $7-500$ and Romania is $32-210 \mathrm{nGy} \cdot \mathrm{h}^{-1}$ [1]. Due to high concentrations of radium and potassium in soil and high exhalation rate of radon the external and internal doses are also higher. This result would be helpful to assess the radiation exposure to human, animal and plants, and radiation related cancer risk.

Table 1. The mean activity concentrations of ${ }^{226} \mathrm{Ra},{ }^{204} \mathrm{Ra}$ and ${ }^{40} \mathrm{~K}$ radionuclides in soil of several districts of Bangladesh and derived radiation hazard parametcrs.

\begin{tabular}{|c|c|c|c|c|c|}
\hline SI. & Location & \# Samples & ${ }^{226} \mathrm{Ra}, \mathrm{Bq} \cdot \mathrm{kg}^{-1}$ & ${ }^{22{ }^{4}} \mathrm{Ra}, \mathrm{Bq} \cdot \mathrm{kg}^{-1}$ & ${ }^{40} \mathrm{~K}, \mathrm{~Bq} \cdot \mathrm{kg}^{-1}$ \\
\hline 1 & Chittagong & 36 & $22.8 \pm 6.1$ & $44.8 \pm 17.5$ & $766 \pm 279$ \\
\hline 2 & Cox's Bazar & 9 & $15.9 \pm 8.9$ & $36.5 \pm 6.3$ & $581 \pm 62$ \\
\hline 3 & Moheshkhali & 9 & $20.9 \pm 3.4$ & $30.5 \pm 2.5$ & $457 \pm 10$ \\
\hline 4 & Comilla & 9 & $40.5 \pm 1.3$ & $71.8 \pm 5.3$ & $741 \pm 131$ \\
\hline 5 & Sylhet & 15 & $23.2 \pm 4.1$ & $61.2 \pm 25.3$ & $392 \pm 131$ \\
\hline 6 & Jaipurhat & 12 & $52.6 \pm 8.2$ & $82.6 \pm 8.6$ & $836 \pm 242$ \\
\hline 7 & Sirajganj & 15 & $48.6 \pm 7.0$ & $72.6 \pm 18.2$ & $904 \pm 115$ \\
\hline 8 & Pabna & 15 & $35.4 \pm 2.7$ & $66.8 \pm 14.7$ & $761 \pm 182$ \\
\hline 9 & Bogra & 15 & $39.2 \pm 16.4$ & $62.8 \pm 16.6$ & $689 \pm 203$ \\
\hline \multirow[t]{2}{*}{10} & Rajshahi & 15 & $31.5 \pm 4.4$ & $64.0 \pm 14.5$ & $468 \pm 241$ \\
\hline & & Mean & $33.1 \pm 12.3$ & $59.4 \pm 16.8$ & $660 \pm 175$ \\
\hline
\end{tabular}


Table 1.(Contd...)

\begin{tabular}{|c|c|c|c|c|c|c|}
\hline Sl. & $\begin{array}{l}{ }^{222} \overline{R n} \\
\text { Emanation } \\
\text { coefficient } \\
\text { Fr }(\%)\end{array}$ & $\begin{array}{l}{ }^{220} \mathrm{Rn} \\
\text { Emanation } \\
\text { coefficient } \\
\text { Fr (\%) }\end{array}$ & $\begin{array}{l}{ }^{222} \text { Rn Mass } \\
\text { exhalation } \\
\text { rate, } \mu \mathrm{Bq} \text {. } \\
\mathrm{kg}^{-1} \cdot \mathrm{s}^{-1}\end{array}$ & $\begin{array}{l}{ }^{220} \mathrm{Rn} \text { Mass } \\
\text { exhalation } \\
\text { rate, mBq. } \\
\mathrm{kg}^{-1} \cdot \mathrm{s}^{-1}\end{array}$ & $\begin{array}{l}{ }^{222} \text { Rn Area } \\
\text { exhalation } \\
\text { rate, } \mathrm{mBq} \\
\mathrm{m}^{-2} \cdot \mathrm{s}^{-1}\end{array}$ & $\begin{array}{l}\text { exn Area } \\
\text { exhalation } \\
\text { rate, } \mathrm{mBq} \text {. } \\
\mathrm{m}^{-2} \cdot \mathrm{s}^{-1}\end{array}$ \\
\hline 1 & $13.4 \pm 6.4$ & $1.09 \pm 0.9$ & $6.3 \pm 1.4$ & $6.0 \pm 1.2$ & $8.5 \pm 4.6$ & $1.7 \pm 3.1$ \\
\hline 2 & $16.0 \pm 3.4$ & $1.06 \pm 0.5$ & $6.8 \pm 1.3$ & $4.7 \pm 1.5$ & $9.2 \pm 1.7$ & $6.3 \pm 2.0$ \\
\hline 3 & $18.5 \pm 1.8$ & $0.93 \pm 0.2$ & $8.2 \pm 2.0$ & $3.6 \pm 0.9$ & $10.9 \pm 2.7$ & $4.7 \pm 1.2$ \\
\hline 4 & $6.2 \pm 0.8$ & $0.36 \pm 0.2$ & $5.2 \pm 0.5$ & $3.2 \pm 1.3$ & $7.0 \pm 0.7$ & $3.4 \pm 2.8$ \\
\hline 5 & $17.9 \pm 5.5$ & $6.87 \pm 1.6$ & $9.4 \pm 1.8$ & $4.5 \pm 12$ & $12.5 \pm 3.2$ & $5.8 \pm 3.2$ \\
\hline 6 & $13.5 \pm 2.9$ & $0.5 \pm 0.09$ & $13.3 \pm 2.2$ & $4.7 \pm 0.5$ & $18.2 \pm 2.4$ & $1.4 \pm 0.2$ \\
\hline 7 & $16.3 \pm 2.8$ & $0.5 \pm 0.2$ & $17.5 \pm 6.7$ & $4.5 \pm 0.8$ & $23.5 \pm 3.0$ & $1.3 \pm 0.2$ \\
\hline 8 & $5.8 \pm 5.0$ & $1.4 \pm 0.8$ & $6.6 \pm 3.0$ & $11.9 \pm 2.2$ & $8.8 \pm 4.5$ & $3.4 \pm 1.7$ \\
\hline 9 & $8.9 \pm 2.9$ & $0.6 \pm 0.1$ & $6.58 \pm 3.0$ & $4.8 \pm 1.2$ & $8.8 \pm 4.5$ & $4.5 \pm 1.0$ \\
\hline 10 & $17.9 \pm 2.8$ & $0.3 \pm 0.07$ & $11.7 \pm 0.6$ & $2.5 \pm 0.7$ & $15.7 \pm 0.7$ & $3.4 \pm 1.0$ \\
\hline Mean & $13.5 \pm 4.8$ & $1.36 \pm 1.9$ & $9.2 \pm 3.9$ & $5.0 \pm 2.6$ & $12.3 \pm 5.3$ & $3.6 \pm 1.8$ \\
\hline
\end{tabular}

\section{References}

[1] UNSCEAR, 1988. Sources, Effects and Risks of Ionizing Radiation, Publication

E.88.IX.7, United Nations Scientific Committee on the Effects of Atomic Radiation. United Nations, New York.

[2] UNSCEAR 1982. Ionizing Radiation: Sources and Biological Effects, Publication E.82.IX.8, United Nations Scientific Committee on the Effects of Atomic Radiation. United Nations, New York.

[3] Kathren R.L. NORM Sources and Their Origins. Applied Radiation and Isotopes, 49(3), 1998, 149-168.

[4] Miah F.K., Molla M. A. R., Alam M.N., Rahaman M.M., Roy S. and Bose S.R., Survey of background level in Bangladesh. Annual Report, Atomic Energy Centre, Dhaka, Bangladesh, 1985.

[5] Chowdhury M.I., Molla M.A.R., Mannan M.A. and Hossain A., Detail survey of

Radiation levels in monazite bearing area of Cox"s Bazar beach and surrounding areas. Nuclear Safety and Radiation Protection Division, BAEC, Dhaka, Bangladesh, 1987.

[6] Tso M.Y.W., Ng C.Y. and Leung J.K.C., Radon release from building materials in Hong Kong. Health Physics, 67(4), 1994, 378-384.

[7] Schotzig U. and Debertin K., Photon emission probabilities per decay of ${ }^{226} \mathrm{Ra}$ and ${ }^{232}$ Th in equilibrium with their daughter products. Applied Radiation and Isotopes. 34, 1983, 533538.

[8] IAEA-295. Measurement of Radionuclides in Food and Environmental Samples. IAEA Technical Report. International Atomic Energy Agency, Vienna, Austria, 1989.

[9] AQCS. Intercomparison Runs Reference Materials, Analytical Quality Control Services, IAEA, Vienna, Austria, 1995. 